\title{
Recomendações quanto ao uso de máscaras/ respiradores de proteção por profissionais de saúde em risco de exposição ao sars-cov-2: scoping review
}

Recommendations regarding the use of protective masks/ respirators by health professionals at risk of exposure to sars-cov-2: scoping review

Recomendaciones con respecto al uso de máscaras/ respiradores protectores por parte de profesionales de la salud en riesgo de exposición al sars-cov-2: scoping review

\section{Resumo}

Objetivo: Analisar as recomendações governamentais e as evidências científicas quanto ao uso de protetores respiratórios por profissionais de saúde no contexto da pandemia por SARS-CoV-2. Método: Scoping Review, seguido o protocolo proposto pelo Instituto Joanna Briggs (JBI), Versão 2020. Foi utilizada a estratégia PCC (População, Conceito e Contexto), para a formulação da seguinte pergunta norteadora: “Quais as recomendações quanto ao uso de máscaras/respiradores de proteção respiratória por profissionais de saúde frente ao risco de contaminação pelo SARS-CoV-2??. Foram realizadas buscas em seis bases de dados internacionais e na literatura cinzenta e em sites governamentais de diferentes países, de julho a agosto de 2020. Resultados: foram incluídos 20 estudos publicados em 2020. Sobre a metodologia dos estudos, 1 (5\%) estudo descritivo, 1 (5\%) revisão narrativa, 2 (10\%) revisão sistemática com meta-análise, 2 revisões sistemáticas (10\%), 8 (40\%) revisão de literatura e $6(30 \%)$ relatório técnico. Conclusão:Há divergências quanto ao: tipo de proteção respiratória em cuidados de rotina, quando não há geração de aerossóis, com estudos que indicam a utilização de máscaras cirúrgicas e outros que recomendam a utilização de um respirador particulado; há indicação de diferentes respiradores particulados de diversos graus de proteção, para o mesmo cenário de exposição clínica, e existe conflito quanto ao cenário de maior exposição para os profissionais de saúde, na discordância de quais procedimentos geram aerossóis.

Palavras-chave: Máscara médica; Respirador N95; Máscara cirúrgica; Equipamento de proteção individual; Profissional de saúde.

\footnotetext{
Abstract

Objective: To analyze governmental recommendations and scientific evidence regarding the use of respiratory protectors by health professionals in the context of the SARS-CoV-2 pandemic. Method: Scoping Review, following the protocol proposed by the Joanna Briggs Institute (JBI), Version 2020. The PCC (Population, Concept and Context) strategy was used to formulate the following guiding question: "What are the recommendations regarding the use of masks? Respiratory protection respirators by health professionals facing the risk of contamination by SARS-CoV-2?". Searches were carried out in six international databases and in gray literature and on government
} 
websites in different countries, from July to August 2020. Results: 20 studies published in 2020 were included. On the methodology of the studies, $1(5 \%)$ study descriptive, $1(5 \%)$ narrative review, $2(10 \%)$ systematic review with metaanalysis, 2 systematic reviews (10\%), $8(40 \%)$ literature review and $6(30 \%)$ technical report. Conclusion: There are differences regarding: type of respiratory protection in routine care, when there is no generation of aerosols, with studies that indicate the use of surgical masks and others that recommend the use of a particulate respirator; there is an indication of different particulate respirators of varying degrees of protection, for the same scenario of clinical exposure, and there is conflict regarding the scenario of greater exposure for health professionals, in disagreement of which procedures generate aerosols.

Keywords: Mask medical; N95 respirator; Surgical mask; Personal protective equipment; Health professional.

\section{Resumen}

Objetivo: Analizar las recomendaciones gubernamentales y la evidencia científica sobre el uso de protectores respiratorios por parte de profesionales de la salud en el contexto de la pandemia SARS-CoV-2. Método: Scoping Review, siguiendo el protocolo propuesto por el Instituto Joanna Briggs (JBI), Versión 2020. Se utilizó la estrategia PCC (Population, Concept and Context) para formular la siguiente pregunta orientadora: “¿Cuáles son las recomendaciones sobre el uso de mascarillas? / respiradores de protección respiratoria por profesionales de la salud que enfrentan el riesgo de contaminación por SARS-CoV-2? ". Se realizaron búsquedas en seis bases de datos internacionales y en literatura gris y en sitios web gubernamentales de diferentes países, de julio a agosto de 2020. Resultados: Se incluyeron 20 estudios publicados en 2020. Sobre la metodología de los estudios, 1 (5\%) estudio descriptiva, 1 (5\%) revisión narrativa, $2(10 \%)$ revisión sistemática con metaanálisis, 2 revisiones sistemáticas (10\%), $8(40 \%)$ revisión de literatura y $6(30 \%)$ informe técnico. Conclusión: Existen diferencias en cuanto a: tipo de protección respiratoria en la atención de rutina, cuando no hay generación de aerosoles, con estudios que indican el uso de mascarillas quirúrgicas y otros que recomiendan el uso de un respirador de partículas; existe una indicación de diferentes respiradores de partículas de diversos grados de protección, para un mismo escenario de exposición clínica, y existe conflicto en cuanto al escenario de mayor exposición para los profesionales de la salud, en desacuerdo sobre qué procedimientos generan aerosoles.

Palabras clave: Mascarilla médica; Respirador N95; Mascarilla quirúrgica; Equipo de protección personal; Profesional de la salud.

\section{Introdução}

Em dezembro de 2019 um novo coronavírus, denominado de síndrome respiratória aguda grave 2 (SARS-CoV2), causador da COVID-19, foi identificado pelo Chinese Center for Disease Controland Prevention (Organização Mundial da Saúde, 2020). De acordo com as evidências atuais, acredita-se que o principal modo de transmissão seja via inalação de gotículas respiratórias ( $>5 \mu \mathrm{m}$ de diâmetro) de vírus exalado de uma pessoa infectada, a menos de 1 metro de distância;assim como pode ocorrer por meio do contato com uma superfície contaminada pelas gotículas respiratórias (fômites). A transmissão aérea por aerossóis ( $\leq 5 \mu \mathrm{m}$ de diâmetro) também é uma das formas de contágio, mas não existem evidências robustas para definir essa rota de transmissão, e até o momento, é descrita em alguns procedimentos específicos de geração de aerossóis (Kaswa, 2020; Jiang et al., 2020; Brasil, 2020).

Os profissionais de saúde constituem um grupo de risco, e representam uma parcela expressiva do número de casos da COVID-19. Estima-se que a proporção de profissionais de saúde infectados, entre os casos confirmados, corresponda à 3,5\% a 20\% (Ha, 2020). No Brasil até o dia 07 de dezembro de 2020 foram confirmados 414.147 casos confirmados e 1.716 óbitos pela COVI-19 em profissionais de saúde. As profissões mais registradas entre os casos confirmados foram as categorias dos técnicos e auxiliares de enfermagem, seguido dos enfermeiros e médicos (Brasil, 2020). O adoecimento de profissionais de saúde é especialmente preocupante, pois pode reduzir os recursos humanos e comprometer a qualidade e potencial de resposta dos serviços de saúde (Teixeira et al., 2020; Helioterio et al., 2020).

Dispositivos de proteção respiratória são essenciais na proteção contra infecções em profissionais de saúde com alto risco de contaminação pelo SARS-CoV-2. Agências nacionais, internacionais de saúde e trabalhos científicos, divulgaram recomendações conflitantes sobre o uso desses EPI's, principalmente quando se referem ao tipo de proteção respiratória a ser adotada em cuidados de rotina. Os motivos que justificam esse panorama, são as incertezas quanto a transmissão aérea do SARS-CoV-2 e os custos. 
Esta revisão de escopo tem por objetivo analisar as recomendações governamentais e as evidências científicas quanto ao uso de protetores respiratórios por profissionais de saúde no contexto da pandemia por SARS-CoV-2.

\section{Metodologia de Pesquisa}

Foi realizada uma revisão de escopo ou "Scoping Review". A revisão de escopo segue um sistema de abordagem útil para explorar a amplitude ou extensão da literatura, mapear e resumir evidências, identificar principais conceitos, teorias e lacunas de conhecimento e informar pesquisas futuras (Munn et al., 2018; Tricco et al., 2018). Foi seguido o protocolo preconizado pelo Joanna Briggs Institute Reviewer's Manual (JBI), versão 2020, e o fluxograma do Preferred Reporting Items for Systematic Reviewsand Meta-analyses (PRISMA), que detalha o processo de seleção dos dados coletados (Peters et al., 2020).

A estratégia população, conceito e contexto (PCC) foi utilizada nesta revisão: P- profissionais de saúde em risco de contaminação por SARS-CoV-2; C- recomendações do uso de máscaras de proteção respiratória para profissional de saúde e C- pandemia de SARS-CoV-2. Essa estratégia foi empregada para responder a pergunta que norteia o estudo: "Quais as recomendações quanto ao uso de máscaras/respiradores de proteção respiratória por profissionais de saúde frente ao risco de contaminação pelo SARS-CoV-2?".

Foram incluídos nesta revisão artigos online disponíveis na íntegra, publicados de janeiro a agosto de 2020; literatura cinzenta, como documentos oficiais, teses, dissertações e manuais de órgãos de saúde nacional e internacional. Excluíram-se editoriais, artigos de opinião e cartas ao editor e leitores.

Foram utilizados os descritores em ciência da saúde (DeCS): "2019-nCoV", "2019 new coronavirus", "2019 novel coronavirus" "novel coronavirus (2019-nCoV)", "SARSCoV-2", "beta coronavirus" "coronavirus infections", "health occupations", "mask", "respiratory protective devices", "personal protective equipment"; e Medical subject headings $(\mathrm{MeSH})$ : “coronavirus", "beta coronavirus", "coronavirus infections", "respiratory protective devices", "mask”, "health occupations", "personal protective equipment".

As buscas foram realizadas em três fases, por três revisores independentes. Os dados foram coletados nos meses de julho e agosto de 2020.

A primeira fase contemplou a formulação das estratégias, seguida da validação em duas bases de dados definidas para essa pesquisa: Cumulative Index to Nursing and Allied Health Literature (CINAHL) e Medline via portal Pubmed. As estratégias validadas estão presentes na Tabela 1. 
Tabela 1. Estratégias de busca utilizadas na primeira etapa de validação.

\begin{tabular}{|c|l|}
\hline $\mathbf{N}^{\mathbf{0}}$ & \multicolumn{1}{|c|}{ ESTRATÉGIAS DE BUSCA } \\
\hline $\mathbf{1}$ & $\begin{array}{l}\text { personal protective equipment AND (coronavirus OR SARS-CoV-2 OR covid-19) AND (surgical mask OR mask } \\
\text { medical) }\end{array}$ \\
\hline $\mathbf{2}$ & personal protective equipment AND (coronavirus OR SARS-CoV-2 OR covid-19) \\
\hline $\mathbf{3}$ & (surgical mask OR N95 respirator) AND (SARS-CoV-2 OR covid-19) \\
\hline $\mathbf{4}$ & (surgical mask OR mask medical OR N95 respirator) AND (SARS-CoV-2 OR covid-19) \\
\hline $\mathbf{5}$ & $\begin{array}{l}\text { (coronavirus OR SARS-CoV-2 OR covid-19) AND personal protective equipment AND (surgical mask OR mask } \\
\text { medical OR N95 respirator) }\end{array}$ \\
\hline $\mathbf{6}$ & SARS-CoV-2 AND (surgical mask OR mask medical OR N95 respirator) \\
\hline $\mathbf{7}$ & $\begin{array}{l}\text { (PPE OR personal protective equipment) AND (coronavirus OR SARS-CoV-2 OR covid-19) AND (surgical mask } \\
\text { OR N95 respirator) }\end{array}$ \\
\hline $\mathbf{8}$ & $\begin{array}{l}\text { personal protective equipment AND (surgical mask OR mask medical OR N95 respirator) AND (SARS-CoV-2 } \\
\text { OR covid-19 AND health professional }\end{array}$ \\
\hline $\mathbf{9}$ & $\begin{array}{l}\text { (coronavirus OR SARS-CoV-2 OR covid-19) AND health professional AND (surgical mask OR mask medical OR } \\
\text { N95 respirator) }\end{array}$ \\
\hline
\end{tabular}

Fonte: Autores (2020).

Das nove estratégias validadas (Tabela 1), elegeu-se para a coleta dos dados apenas as estratégias número 1 e 3 , porque conseguiram filtrar um número maior de artigos que atendiam aos critérios de elegibilidade para essa pesquisa.

A partir disso, iniciou-se a segunda fase da pesquisa. Essa etapa consistiu em uma busca mais abrangente. Para a realização das coletas, nessa fase, foi consultado as bases de dados Medline (Pubmed), Web Of Science, CINAHL, SCOPUS e Biblioteca Cochrane. A literatura cinzenta, consistiu na pesquisa no Google Scholar, ProQuest Dissertations Theses; também foram consultados sites governamentais de vários países, o site da Organização Mundial da Saúde (OMS), Centro de Prevenção e Controle de Doenças (CDC) dos Estados Unidos, Centro Europeu de Prevenção e Controle de Doenças (ECDC), e a Agência Nacional de Vigilância Sanitária (Anvisa) do Brasil.

$\mathrm{Na}$ terceira fase, foram realizadas buscas nas referências de cada artigo incluído no estudo, com o objetivo de encontrar algum estudo que, por ventura, não tenha sido capturado na fase de buscas anterior, e que atende ao objetivo dessa pesquisa.

Os títulos e os resumos dos estudos foram lidos e analisados para identificar os elegíveis para a revisão e posterior leitura na íntegra. Os estudos identificados foram agrupados e exportados para o Solftware EndNote, que é um gerenciador de referências, para filtrar e eliminar os artigos duplicados.

\section{Resultados}

A busca nas bases de dados identificou 3.655 estudos relevantes. Na literatura cinzenta, 12 documentos foram identificados. Na terceira fase de buscas, todas as referências dos estudos elegíveis, provenientes das bases de dados, foram consultadas para identificar estudos relevantes que não apareceram na busca anterior. Para realizar a leitura na íntegra, 61 estudos foram elegíveis, e desses, 20 foram selecionados para integrar a amostra. A Figura 1 especifica o processo de seleção dos artigos e relatórios técnicos por meio de um fluxograma, baseado no modelo PRISMA. 
Research, Society and Development, v. 10, n. 1, e16710111628, 2021

(CC BY 4.0) | ISSN 2525-3409 | DOI: http://dx.doi.org/10.33448/rsd-v10i1.11628

Figura 1. Fluxograma PRISMA do processo de seleção dos artigos/ estudos para revisão de escopo.

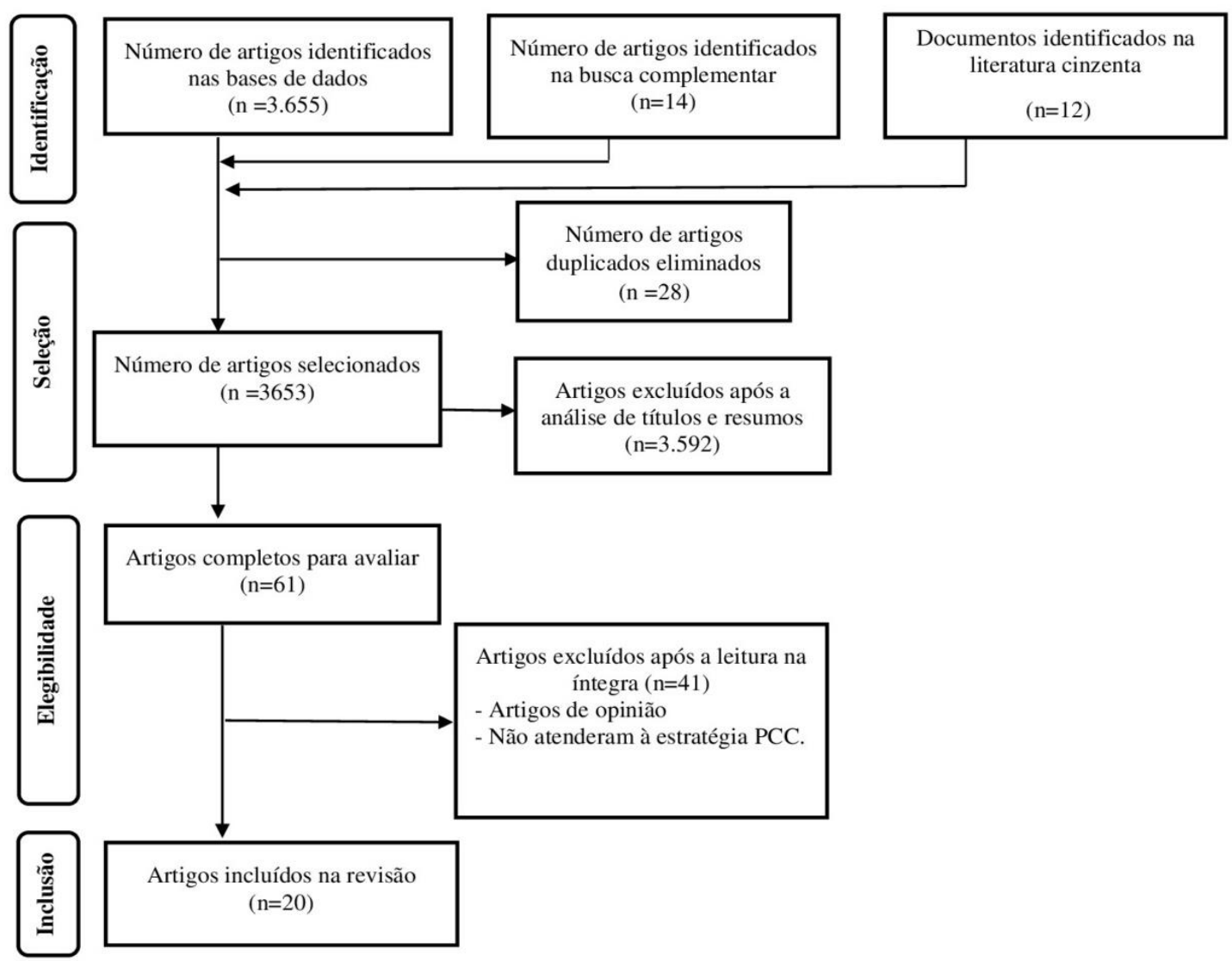

Fonte: Adaptado de Moher et al(2009). 
Os artigos científicos incluídos na revisão de escopo, provenientes das bases de dados, totalizam 14 estudos, que foram categorizados no Quadro1. Foram extraídos dados referentes ao: título, autor, país / língua, objetivos / finalidades, metodologia, resultados, recomendações e conclusão.

Quadro 1. Descrição das recomendações do uso de máscaras/respiradores para os profissionais de saúde em risco de exposição ao SARS-CoV-2.

\begin{tabular}{|c|c|c|c|c|c|c|}
\hline $\begin{array}{c}\text { TÍTULO } \\
\text { (AUTOR, ANO) }\end{array}$ & $\begin{array}{l}\text { PAÍS/ } \\
\text { LÍNGUA }\end{array}$ & $\begin{array}{c}\text { OBJETIVOS/ } \\
\text { FINALIDADES }\end{array}$ & MÉTODO & RESULTADOS & $\begin{array}{l}\text { RECOMENDAÇÕES/ } \\
\text { TIPO DE MÁSCARA/ } \\
\text { RESPIRADOR }\end{array}$ & CONCLUSÃO \\
\hline $\begin{array}{l}\text { E1. What face mask } \\
\text { for what use in the } \\
\text { context of the } \\
\text { COVID-19 } \\
\text { pandemic? The } \\
\text { French guidelines } \\
\text { (Lepelletier \& } \\
\text { Grandbastien et al., } \\
\text { 2020). }\end{array}$ & $\begin{array}{l}\text { França/ } \\
\text { Inglesa }\end{array}$ & $\begin{array}{l}\text { Apresentar as diretrizes } \\
\text { francesas sobre as } \\
\text { indicações de uso de } \\
\text { máscara cirúrgica e } \\
\text { respiradores (PFF) com } \\
\text { o objetivo de } \\
\text { racionalizar o uso de } \\
\text { máscaras e evitar sua } \\
\text { escassez. }\end{array}$ & Estudo descritivo & $\begin{array}{l}\text { Máscara cirúrgica: para único, } \\
\text { trocar a cada } 4 \text { horas, em casos } \\
\text { sugestivos/ confirmados da } \\
\text { COVID-19, e na ausência de } \\
\text { procedimentos invasivos no } \\
\text { trato respiratório. Respirador: } \\
\text { PFF2 em procedimentos } \\
\text { invasivos, que podem gerar } \\
\text { aerossóis, e especificam quais os } \\
\text { procedimentos. O tempo de uso } \\
\text { deve ser } 8 \text { h em um único dia. }\end{array}$ & Máscara cirúrgica e PFF2 & $\begin{array}{l}\text { Máscara cirúrgica para a } \\
\text { exposição dos profissionais à } \\
\text { gotículas potencialmente } \\
\text { infecciosas do paciente. O uso } \\
\text { de um PFF é estritamente } \\
\text { reservado para profissionais } \\
\text { expostos a aerossóis. }\end{array}$ \\
\hline $\begin{array}{l}\text { E2. Risk of SARS- } \\
\text { CoV-2 transmission } \\
\text { by aerosols, the } \\
\text { rational use of masks, } \\
\text { and protection of } \\
\text { healthcare workers } \\
\text { from COVID-19 } \\
\text { (Sommerstein, R et } \\
\text { al., 2020). }\end{array}$ & $\begin{array}{l}\text { Suíça/ } \\
\text { Inglesa }\end{array}$ & 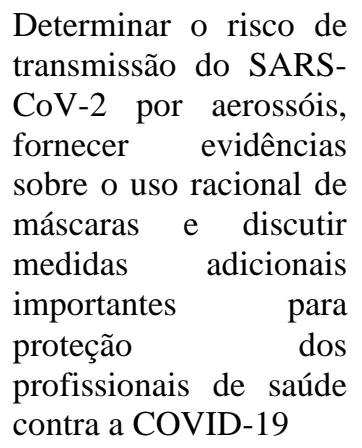 & $\begin{array}{c}\text { Revisão de } \\
\text { literatura e opinião } \\
\text { de especialistas. }\end{array}$ & \begin{tabular}{l}
\multicolumn{3}{c}{ Máscara cirúrgica: (tipo 2): usar } \\
por no máximo 8 horas. \\
Respirador: $\quad$ PFF2 $r$ para \\
procedimentos \\
aerossóis.
\end{tabular} & Máscara cirúrgica e PFF2 & $\begin{array}{l}\text { Máscaras cirúrgicas de padrão } \\
\text { de alta qualidade (tipo II) } \\
\text { parecem ser tão eficazes } \\
\text { quanto as máscaras PFF2 na } \\
\text { prevenção de infecções virais } \\
\text { associadas a gotículas de } \\
\text { profissionais de saúde, } \\
\text { conforme relatado por } \\
\text { influenza ou SARS. }\end{array}$ \\
\hline $\begin{array}{c}\text { E3. Use of personal } \\
\text { protective equipment } \\
\text { during the COVID-19 } \\
\text { pandemic }\end{array}$ & $\begin{array}{l}\text { Reino } \\
\text { Unido/ }\end{array}$ & 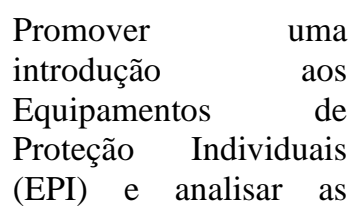 & $\begin{array}{l}\text { Revisão de } \\
\text { literatura }\end{array}$ & $\begin{array}{l}\text { Respiradores: PFF2 e N95 } \\
\text { podem ser usados se os PFF3 } \\
\text { não estiverem disponíveis. } \\
\text { Máscaras cirúrgicas: proteção } \\
\text { contra agentes infecciosos }\end{array}$ & $\begin{array}{l}\text { Máscara cirúrgica, } \\
\text { N95/PFF2 e PFF3 }\end{array}$ & $\begin{array}{l}\text { Funcionários que trabalham } \\
\text { sem o EPI apropriado, ou } \\
\text { usando o EPI de maneira } \\
\text { inadequada, correm um risco } \\
\text { significativo de infecção, }\end{array}$ \\
\hline
\end{tabular}


Research, Society and Development, v. 10, n. 1, e16710111628, 2021

(CC BY 4.0) | ISSN 2525-3409 | DOI: http://dx.doi.org/10.33448/rsd-v10i1.11628

\begin{tabular}{|c|c|c|c|c|c|c|}
\hline $\begin{array}{c}\text { (Gordon \& } \\
\text { Thompson, 2020). }\end{array}$ & Inglesa & $\begin{array}{l}\text { diretrizes mais recentes } \\
\text { no contexto do cuidado } \\
\text { de enfermagem de } \\
\text { pacientes com COVID- } \\
19 \text { no Reino Unido. }\end{array}$ & & transmitidos por gotículas. & & $\begin{array}{l}\text { potencialmente aumentando a } \\
\text { transmissão. }\end{array}$ \\
\hline $\begin{array}{l}\text { E4. Evaluating the } \\
\text { national PPE } \\
\text { guidance for NHS } \\
\text { healthcare workers } \\
\text { during the COVID-19 } \\
\text { pandemic } \\
\text { (Thomas J. P et al., } \\
\text { 2020). }\end{array}$ & $\begin{array}{l}\text { Reino } \\
\text { Unido/ } \\
\text { Inglesa }\end{array}$ & $\begin{array}{l}\text { Avaliar a orientação } \\
\text { nacional de EPI para } \\
\text { saúde dos trabalhadores } \\
\text { do Serviço Nacional de } \\
\text { Saúde (NHS) } \\
\text { durante a pandemia } \\
\text { COVID-19 }\end{array}$ & $\begin{array}{c}\text { Revisão de } \\
\text { literatura e opinião } \\
\text { de especialistas }\end{array}$ & $\begin{array}{l}\text { Respiradores: N95 ou PFF2/3 } \\
\text { para profissionais de saúde do } \\
\text { na assistência de qualquer caso } \\
\text { suspeito ou caso confirmado da } \\
\text { COVID-19. }\end{array}$ & $\begin{array}{l}\text { Máscaras cirúrgicas e } \\
\text { N95 ou PFF2/3 }\end{array}$ & $\begin{array}{l}\text { Revisar urgente as diretrizes } \\
\text { de recomendação nacionais } \\
\text { sobre os EPI's indicados aos } \\
\text { profissionais de saúde, com a } \\
\text { finalidade de garantir proteção } \\
\text { suficiente durante a pandemia. }\end{array}$ \\
\hline $\begin{array}{l}\text { E5. Medical mask or } \\
\text { N95 respirator: when } \\
\text { and how to use? } \\
\text { (Azap \& Erdinç, } \\
\text { 2020). }\end{array}$ & $\begin{array}{l}\text { Turquia/ } \\
\text { Inglesa }\end{array}$ & $\begin{array}{l}\text { Apresentar e avaliar a } \\
\text { diretriz do comitê do } \\
\text { Ministério da saúde da } \\
\text { Turquia, sobre o uso de } \\
\text { máscara pelos } \\
\text { profissionais de saúde, } \\
\text { no contexto de } \\
\text { pandemia pelo COVID- } \\
19\end{array}$ & $\begin{array}{c}\text { Revisão de } \\
\text { literatura e opinião } \\
\text { de especialistas }\end{array}$ & $\begin{array}{l}\text { Máscara cirúrgica: a } 1 \mathrm{~m} \text { de } \\
\text { distância do paciente com } \\
\text { sintomas sugestivos de COVID- } \\
19 \text { ou confirmado, que não } \\
\text { incluam procedimentos } \\
\text { geradores de aerossol. } \\
\text { Respirador N95/PFF2: em } \\
\text { procedimentos geradores de } \\
\text { aerossol, ou em ambientes que } \\
\text { esses procedimentos sejam } \\
\text { frequentes, e na manipulação de } \\
\text { amostras respiratórias. }\end{array}$ & $\begin{array}{c}\text { Máscara cirúrgica/ } \\
\text { Respirador N95/PFF2 }\end{array}$ & $\begin{array}{l}\text { O tipo de máscara usada } \\
\text { durante o atendimento ao } \\
\text { paciente, irá variar de acordo } \\
\text { com o cenário/atividade } \\
\text { desempenhada pelo } \\
\text { profissional de saúde. }\end{array}$ \\
\hline
\end{tabular}




\begin{tabular}{|c|c|c|c|c|c|c|}
\hline $\begin{array}{l}\text { E6. Medical masks vs } \\
\text { N95 respirators for } \\
\text { preventing COVID-19 } \\
\text { in healthcare } \\
\text { workers: A systematic } \\
\text { review and meta- } \\
\text { analysis of } \\
\text { randomized trials } \\
\text { (Bartoszko, J.J et al., } \\
\text { 2020). }\end{array}$ & $\begin{array}{l}\text { Canadá/ } \\
\text { Inglesa }\end{array}$ & $\begin{array}{l}\text { Comparar a eficácia } \\
\text { das máscaras cirúrgicas } \\
\text { com respiradores N95, } \\
\text { na prevenção de } \\
\text { infecção } \\
\text { confirmada e doença } \\
\text { respiratória, incluindo } \\
\text { coronavírus, } \\
\text { especificamente em } \\
\text { profissionais de saúde. }\end{array}$ & $\begin{array}{l}\text { Revisão sistemática } \\
\text { e meta-análise de } \\
\text { ensaios } \\
\text { randomizados }\end{array}$ & 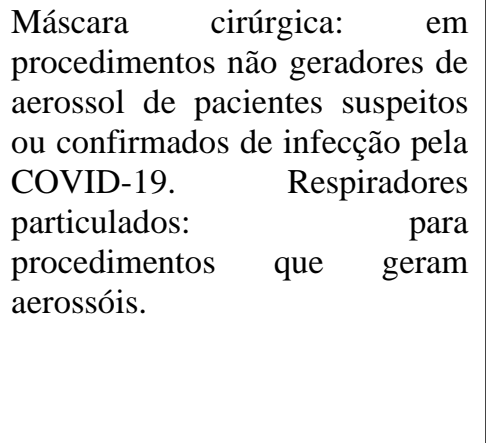 & $\begin{array}{c}\text { Máscara cirúrgica/ } \\
\text { Respirador N95/PFF2 }\end{array}$ & $\begin{array}{l}\text { O estudo não foi capaz de } \\
\text { realizar a meta-análise para } \\
\text { infecção por coronavírus } \\
\text { especificamente. }\end{array}$ \\
\hline $\begin{array}{l}\text { E7. Personal } \\
\text { protective equipment } \\
\text { during the } \\
\text { coronavirus disease } \\
\text { (COVID) } 2019 \\
\text { pandemic }-a \\
\text { narrative review } \\
\text { (Cook T. M, 2020). }\end{array}$ & $\begin{array}{l}\text { Reino } \\
\text { Unido/ } \\
\text { Inglesa }\end{array}$ & $\begin{array}{l}\text { Discutir os modos de } \\
\text { transmissão } \\
\text { COVID-19, analisar } \\
\text { qual EPI utilizar, de } \\
\text { acordo com o modo de } \\
\text { transmissão, com foco } \\
\text { nas recomendações } \\
\text { emitidas pelo Reino } \\
\text { Unido. }\end{array}$ & Revisão narrativa & $\begin{array}{l}\text { Máscara cirúrgica IIR: para a } \\
\text { equipe de profissionais de saúde } \\
\text { na mesma sala que os pacientes } \\
\text { com COVID-19, e onde os } \\
\text { procedimentos de geração de } \\
\text { aerossol não são realizados, a } \\
\text { dois metros de distância do } \\
\text { paciente. Respirador PFF3: } \\
\text { quando procedimentos de } \\
\text { geração de aerossol estão sendo } \\
\text { realizados. }\end{array}$ & $\begin{array}{l}\text { Máscara cirúrgica } \\
\text { resistente a fluidos (tipo } \\
\text { IIR)/ máscara PFF3 }\end{array}$ & $\begin{array}{l}\text { As evidências quanto ao uso } \\
\text { de um respirador } \\
\text { PFF3/PFF2/N95, em vez de } \\
\text { uma máscara cirúrgica não são } \\
\text { robustas. A classificação dos } \\
\text { procedimentos geradores de } \\
\text { aerossol também é imperfeita.. }\end{array}$ \\
\hline $\begin{array}{c}\text { E8. Respiratory } \\
\text { protection for health } \\
\text { care workers: A } 2020 \\
\text { COVID-19 } \\
\text { perspective } \\
\text { (Petsonk \& Haber, } \\
\text { 2020). }\end{array}$ & $\begin{array}{l}\text { Estados } \\
\text { Unidos da } \\
\text { América/ } \\
\text { Inglesa }\end{array}$ & $\begin{array}{l}\text { Avaliar as práticas de } \\
\text { proteção individual } \\
\text { respiratória ra de } \\
\text { contingenciamento de } \\
\text { crise versus as } \\
\text { melhores práticas } \\
\text { convencionais aceitas, } \\
\text { abordando as } \\
\text { orientações do Instituto } \\
\text { Nacional de Segurança } \\
\text { Ocupacional (NIOSH). }\end{array}$ & $\begin{array}{c}\text { Revisão de } \\
\text { literatura e opinião } \\
\text { de especialistas }\end{array}$ & $\begin{array}{l}\text { Respiradores: utilizar a N95 em. } \\
\text { procedimentos de alto risco, é } \\
\text { mais confiável PAPR } \\
\text { reutilizável, as vantagens } \\
\text { oferecidas são atribuídas ao } \\
\text { maior fator de proteção em } \\
\text { comparação } \\
\text { respiradores. }\end{array}$ & $\begin{array}{l}\text { N95 e Respiradores } \\
\text { purificadores de ar } \\
\text { (PAPRs) }\end{array}$ & $\begin{array}{l}\text { Oferecer a melhor proteção } \\
\text { respiratória, com base na } \\
\text { ciência de ponta, tecnologia } \\
\text { comprovada, treinamento } \\
\text { eficaz e gerenciamento de } \\
\text { programa profissional. }\end{array}$ \\
\hline
\end{tabular}




\begin{tabular}{|c|c|c|c|c|c|c|}
\hline $\begin{array}{l}\text { E9. COVID-19 } \\
\text { coronavirus: } \\
\text { recommended } \\
\text { personal protective } \\
\text { for the orthopaedic } \\
\text { and trauma surgeon } \\
\text { (Hirschim, Ann, M.T. } \\
\text { et al, 2020). }\end{array}$ & $\begin{array}{l}\text { Austria, } \\
\text { Luxemburg } \\
\text { o, Suíça, } \\
\text { Alemanha, } \\
\text { Reino } \\
\text { Unido }\end{array}$ & 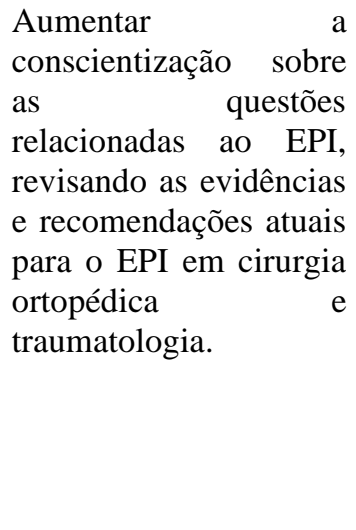 & Revisão Sistemática & 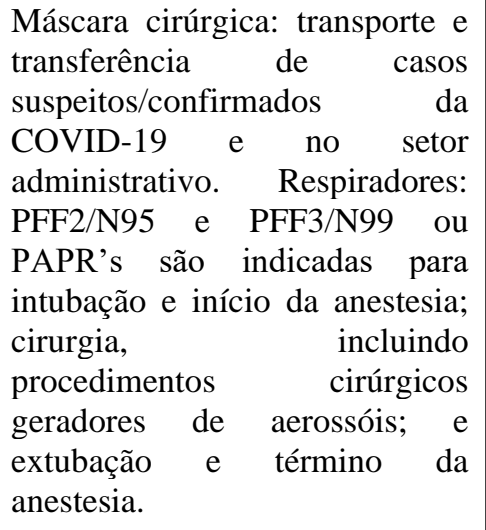 & $\begin{array}{c}\text { Máscara cirúrgica, } \\
\text { PFF2/N95, PFF3N99 e } \\
\text { PAPR }\end{array}$ & $\begin{array}{l}\text { Em caso de infecção } \\
\text { comprovada ou suspeita da } \\
\text { COVID-19, os cirurgiões } \\
\text { ortopédicos devem usar } \\
\text { máscaras respiratórias PFF2/3 } \\
\text { ou N95/99. }\end{array}$ \\
\hline $\begin{array}{c}\text { E10. Role of } \\
\text { respirators in } \\
\text { controlling the spread } \\
\text { of novel coronavirus } \\
\text { (COVID-19) amongst } \\
\text { dental healthcare } \\
\text { providers: a review } \\
\text { (Umer, F.et al., } \\
\text { 2020). }\end{array}$ & $\begin{array}{l}\text { Paquistão } \\
\text { /Inglesa }\end{array}$ & $\begin{array}{l}\text { Discutir sobre os } \\
\text { respiradores existentes, } \\
\text { sua finalidade, tipos, } \\
\text { eficiência clínica e uso } \\
\text { adequado e técnicas de } \\
\text { troca. }\end{array}$ & $\begin{array}{l}\text { Revisão de } \\
\text { literatura }\end{array}$ & $\begin{array}{l}\text { Respiradores: provaram oferecer } \\
\text { melhor proteção contra } \\
\text { gotículas, aerossóis e penetração } \\
\text { de fluidos e que são capazes de } \\
\text { formar uma vedação apertada ao } \\
\text { redor da boca e do nariz, como o } \\
\text { FFRs e PAPRs. }\end{array}$ & $\begin{array}{l}\text { Respiradores de máscara } \\
\text { facial de filtragem } \\
\text { (FFRs), em especial o } \\
\text { N95 }\end{array}$ & $\begin{array}{l}\text { É essencial usar FFRs durante } \\
\text { a pandemia de COVID-19 } \\
\text { para prevenir a transmissão de } \\
\text { aerossóis e gotículas já que } \\
\text { comprovadamente oferecem } \\
\text { resistência contra fluidos. }\end{array}$ \\
\hline $\begin{array}{c}\text { E11. Personal } \\
\text { Protective } \\
\text { Equipament for } \\
\text { Healthcare Workers } \\
\text { during the COVID-19 } \\
\text { Pandemic. } \\
\text { (Park, Sun Hee, } \\
\text { 2020). }\end{array}$ & $\begin{array}{l}\text { Coreia do } \\
\text { Sul/ } \\
\text { Inglesa. }\end{array}$ & $\begin{array}{l}\text { Propor análise em } \\
\text { relação às evidências } \\
\text { sobre o modo de } \\
\text { transmissão do SARS- } \\
\text { CoV-2, comparar as } \\
\text { recomendações atuais } \\
\text { de PPE da OMS com as } \\
\text { da Coréia, e discutir os } \\
\text { requisitos de padrão e } \\
\text { seleção adequada de } \\
\text { EPI. }\end{array}$ & $\begin{array}{l}\text { Revisão de } \\
\text { Literatura }\end{array}$ & \begin{tabular}{llr}
\multicolumn{3}{l}{ Máscaras cirúrgicas: em contato } \\
com suspeitos & ou com a \\
COVID-19 & confirmados: \\
Respiradores: & N95 & ou \\
equivalentes & usar & em \\
procedimentos & geradores & de \\
aerossóis. & &
\end{tabular} & $\begin{array}{c}\text { Máscaras cirúrgicas e } \\
\text { N95. }\end{array}$ & $\begin{array}{l}\text { A seleção do EPI adequado } \\
\text { deve ser baseada em um risco } \\
\text { direto da avaliação da } \\
\text { extensão e duração da } \\
\text { exposição e as propriedades do } \\
\text { EPI necessárias para proteção. }\end{array}$ \\
\hline
\end{tabular}




\begin{tabular}{|c|c|c|c|c|c|c|}
\hline $\begin{array}{l}\text { E12. Respiratory } \\
\text { Protection } \\
\text { Considerations for } \\
\text { Healthcare Workers } \\
\text { During the COVID- } \\
19 \text { Pandemic } \\
\text { (Friese, C.R et al., } \\
\text { 2020) }\end{array}$ & $\begin{array}{l}\text { Estados } \\
\text { Unidos da } \\
\text { América/ } \\
\text { Inglesa }\end{array}$ & $\begin{array}{l}\text { Propor estratégias e } \\
\text { ações de longo prazo a } \\
\text { serem adotadas para } \\
\text { proteger os } \\
\text { trabalhadores da saúde } \\
\text { de COVID-19 e futuras } \\
\text { pandemias. }\end{array}$ & $\begin{array}{c}\text { Revisão de } \\
\text { literatura e opinião } \\
\text { de especialistas. }\end{array}$ & $\begin{array}{l}\text { Respiradores: N95 ao prestar } \\
\text { atendimento a pacientes com } \\
\text { COVID-19 confirmado ou } \\
\text { suspeito. Respiradores com } \\
\text { níveis mais altos de proteção, } \\
\text { como respiradores purificadores } \\
\text { de ar elétricos, podem ser } \\
\text { necessários. }\end{array}$ & Respirador N95/PFF2 & $\begin{array}{l}\text { Ofertar em quantidade } \\
\text { suficiente os respiradores N95 } \\
\text { para profissionais de saúde } \\
\text { que prestam atendimento a } \\
\text { pacientes com COVID-19 } \\
\text { confirmado ou suspeito. }\end{array}$ \\
\hline $\begin{array}{l}\text { E13. A systematic } \\
\text { review and meta- } \\
\text { analysis of the } \\
\text { efficacy of medical } \\
\text { masks and N95 } \\
\text { respirators for } \\
\text { protection against } \\
\text { respiratory infectious } \\
\text { diseases, including } \\
\text { COVID-19 in medical } \\
\text { staff } \\
\text { (M.M, Gao-Hong Wu } \\
\text { et al., 2020) }\end{array}$ & $\begin{array}{l}\text { China/ } \\
\text { Inglesa }\end{array}$ & $\begin{array}{l}\text { Conduzir uma meta- } \\
\text { análise abrangente da } \\
\text { eficácia do respirador } \\
\text { N95 e máscaras } \\
\text { cirúrgicas para proteção } \\
\text { contra doenças } \\
\text { respiratórias } \\
\text { infecciosas, incluindo } \\
\text { COVID-19, e fornecer } \\
\text { base científica para } \\
\text { formulação de políticas } \\
\text { relacionadas ao uso de } \\
\text { máscaras e outros } \\
\text { EPIs. }\end{array}$ & $\begin{array}{l}\text { Revisão sistemática } \\
\text { e meta-análise }\end{array}$ & $\begin{array}{l}\text { Respiradores: N95 para proteção } \\
\text { contra aerossóis.. Há evidências } \\
\text { de que máscaras cirúrgicas e os } \\
\text { respiradores N95 têm eficácia de } \\
\text { proteção semelhante. }\end{array}$ & $\begin{array}{l}\text { Máscaras cirúrgicas/ } \\
\text { Respirador N95 }\end{array}$ & $\begin{array}{l}\text { Os efeitos protetores dos } \\
\text { respiradores N95 e máscaras } \\
\text { respiratórias contra o SARS- } \\
\text { CoV-2 não foram estudados } \\
\text { especificamente contra o } \\
\text { SARS-CoV-2. }\end{array}$ \\
\hline $\begin{array}{c}\text { E14. Infectious } \\
\text { Diseases Society of } \\
\text { America Guidelines } \\
\text { on Infection } \\
\text { Prevention for Health } \\
\text { Care Personnel } \\
\text { Caring for Patients } \\
\text { with Suspected or } \\
\text { Known COVID-19 } \\
\text { (Lynch, John. B et al., } \\
\text { 2020). }\end{array}$ & $\begin{array}{c}\text { Estados } \\
\text { Unidos da } \\
\text { América/In } \\
\text { glesa }\end{array}$ & $\begin{array}{l}\text { Desenvolver diretrizes } \\
\text { rápidas baseadas em } \\
\text { evidências destinadas a } \\
\text { apoiar os profissionais } \\
\text { de saúde em suas } \\
\text { decisões sobre a } \\
\text { prevenção de infecções } \\
\text { ao cuidar de pacientes } \\
\text { com COVID-19 }\end{array}$ & Revisão sistemática & $\begin{array}{l}\text { Máscara cirúrgica ou respirador } \\
\text { N95 (ou N95 ou PAPR) em } \\
\text { comparação com nenhuma } \\
\text { máscara como parte do EPI } \\
\text { apropriado. Em procedimentos } \\
\text { geradores de aerossol em } \\
\text { pacientes com COVID-19 } \\
\text { suspeitos ou confirmados usar } \\
\text { um respirador N95/e N99 ou } \\
\text { PAPR. }\end{array}$ & $\begin{array}{c}\text { Máscara cirúrgica/ } \\
\text { Respirador } \\
\text { N95/N99/PAPR }\end{array}$ & $\begin{array}{l}\text { Estudos clínicos adicionais são } \\
\text { necessários para informar } \\
\text { nossa compreensão da } \\
\text { transmissão respiratória do } \\
\text { SARS-CoV-2 no ambiente de } \\
\text { saúde. }\end{array}$ \\
\hline
\end{tabular}

Fonte:Autores (2020). 
Os estudos da literatura cinzenta, extraídos do Google Scholar, ProQuest Dissertations Theses, órgãos governamentais e agências de saúde, foram incluídos no Quadro 2, totalizando 6 documentos.

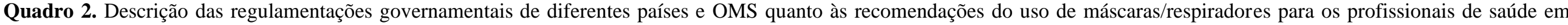
risco de exposição ao SARS-CoV-2.

\begin{tabular}{|c|c|c|c|c|c|c|c|}
\hline $\begin{array}{c}\text { ÓRGÃO } \\
\text { RESPONSÁVEL }\end{array}$ & $\begin{array}{l}\text { TÍTULO } \\
\text { AUTOR(RES) } \\
\text { /ANO }\end{array}$ & $\begin{array}{c}\text { PAÍS/ } \\
\text { LÍNGUA }\end{array}$ & $\begin{array}{r}\text { OBJETIVOS/ } \\
\text { FINALIDADES }\end{array}$ & MÉTODO & RESULTADOS & $\begin{array}{c}\text { RECOMENDAÇÕES/ } \\
\text { TIPO DE MÁSCARA/ } \\
\text { RESPIRADOR }\end{array}$ & CONCLUSÃO \\
\hline $\begin{array}{l}\text { Agência } \\
\text { Nacional de } \\
\text { Vigilância } \\
\text { Sanitária } \\
\text { (ANVISA) }\end{array}$ & \begin{tabular}{|c|} 
ORIENTAÇÕES \\
PARA PREVENÇÃO \\
E VIGILÂNCIA \\
EPIDEMIOLÓGICA \\
DAS INFECÇÕES \\
POR SARS-CoV-2 \\
(COVID-19) DENTRO \\
DOS SERVIÇOS DE \\
SAÚDE \\
Equipe Técnica \\
GVIMS/GGTES \\
/2020
\end{tabular} & $\begin{array}{c}\text { Brasil/ } \\
\text { Português }\end{array}$ & $\begin{array}{l}\text { Destacar ações } \\
\text { importantes para a } \\
\text { prevenção e o controle } \\
\text { de surtos de COVID- } \\
19 \text { dentro dos serviços } \\
\text { de saúde. }\end{array}$ & $\begin{array}{l}\text { Relatório } \\
\text { técnico }\end{array}$ & $\begin{array}{l}\text { Máscara de tecido: em áreas } \\
\text { administrativas e triagem; } \\
\text { Máscara cirúrgica: para } \\
\text { assistência ao paciente } \\
\text { quando estiver, no mínimo a } \\
1 \text { m de distância. Respirador: } \\
\text { para procedimentos que } \\
\text { possam gerar aerossóis, não } \\
\text { especifica quais. }\end{array}$ & $\begin{array}{l}\text { Máscara de tecido/ } \\
\text { máscara } \\
\text { cirúrgica/N95/PFF2 }\end{array}$ & $\begin{array}{l}\text { As orientações são } \\
\text { baseadas no que se sabe até } \\
\text { o momento, podendo ser } \\
\text { atualizada ao surgimento de } \\
\text { novas evidências } \\
\text { científicas. }\end{array}$ \\
\hline $\begin{array}{c}\text { Centro Europeu } \\
\text { de Prevenção e } \\
\text { Controle de } \\
\text { Doenças (ECDC) }\end{array}$ & \begin{tabular}{|c|} 
GUIDANCE FOR \\
WEARING AND \\
REMOVING \\
PERSONAL \\
PROTECTIVE \\
EQUIPMENT IN \\
HEALTHCARE \\
SETTINGS FOR THE \\
CARE OF PATIENTS \\
WITH SUSPECTED \\
OR CONFIRMED \\
COVID-19
\end{tabular} & $\begin{array}{l}\text { Estocolmo/ } \\
\text { Inglesa }\end{array}$ & $\begin{array}{lrr}\text { Apresentar } & \text { o } \\
\text { equipamento } & \text { de } \\
\text { proteção individual } \\
\text { (EPI) mínimo } & \text { é } \\
\text { necessário para } & \text { a } \\
\text { gestão de } & \text { casos } \\
\text { suspeitos } & \text { ou } \\
\text { confirmados } & \text { de } \\
\text { COVID-19; } & \\
\text { sensibilizar } & \text { os } \\
\text { profissionais de saúde } \\
\text { para os aspectos }\end{array}$ & $\begin{array}{l}\text { Relatório } \\
\text { técnico }\end{array}$ & 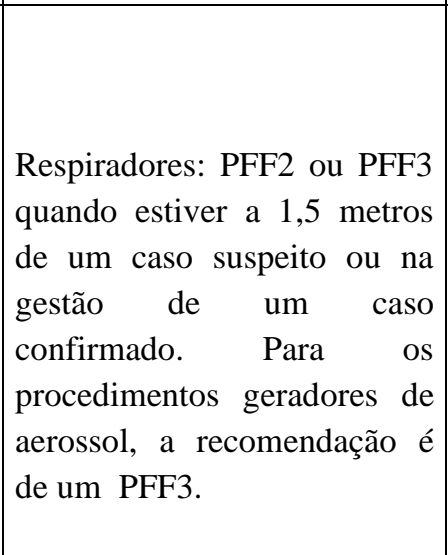 & PFF2/PFF3 & $\begin{array}{l}\text { O documento baseia-se nos } \\
\text { conhecimentos atuais sobre } \\
\text { o SARS-CoV-2 e nas boas } \\
\text { práticas aplicáveis à } \\
\text { utilização do EPI. }\end{array}$ \\
\hline
\end{tabular}


Research, Society and Development, v. 10, n. 1, e16710111628, 2021

(CC BY 4.0) | ISSN 2525-3409 | DOI: http://dx.doi.org/10.33448/rsd-v10i1.11628

\begin{tabular}{|c|c|c|c|c|c|c|c|}
\hline & $\begin{array}{l}\text { Adihoch, Cornelia; } \\
\quad \text { et al. } / 2020\end{array}$ & & $\begin{array}{l}\text { críticos da colocação e } \\
\text { remoção do EPI. }\end{array}$ & & & & \\
\hline $\begin{array}{c}\text { Departamento de } \\
\text { Saúde } \\
\text { Australiano }\end{array}$ & \begin{tabular}{|c} 
GUIDANCE ON \\
THE USE OF \\
PERSONAL \\
PROTECTIVE \\
EQUIPMENT (PPE) \\
IN HOSPITALS \\
DURING THE \\
COVID-19 \\
OUTBREAK \\
The Infection \\
Control Expert Group/ \\
2020
\end{tabular} & $\begin{array}{l}\text { Austrália/ } \\
\text { Inglesa }\end{array}$ & $\begin{array}{|lrr|}\text { Fornecer } & \text { orientação } \\
\text { sobre o uso } & \text { de } \\
\text { equipamentos } & \text { de } \\
\text { proteção } & \text { individual } \\
\text { (EPI) em } & \text { ambientes } \\
\text { hospitalares } & \text { durante o } \\
\text { surto de COVID-19. }\end{array}$ & $\begin{array}{l}\text { Relatório } \\
\text { técnico }\end{array}$ & 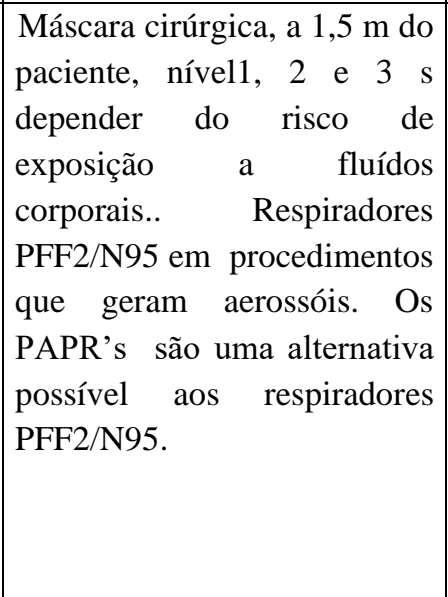 & $\begin{array}{l}\text { Máscaras cirúrgicas de } \\
\text { nível 1,2 e 3/ } \\
\text { Respiradores PFF2/n95/ } \\
\text { Respiradores } \\
\text { purificadores de ar } \\
\text { (PAPR). }\end{array}$ & $\begin{array}{l}\text { Seguir as precauções } \\
\text { baseadas na transmissão, e } \\
\text { que fornece proteção } \\
\text { esperada aos profissionais } \\
\text { de saúde. }\end{array}$ \\
\hline $\begin{array}{c}\text { Organização } \\
\text { Mundial de Saúde } \\
\text { (OMS) }\end{array}$ & $\begin{array}{c}\text { ADVICE ON THE } \\
\text { USE OF MASKS IN } \\
\text { THE CONTEXT OF } \\
\text { COVID-19 } \\
\text { OMS/2020 }\end{array}$ & $\begin{array}{l}\text { Genebra/ } \\
\text { Inglesa }\end{array}$ & $\begin{array}{l}\text { Orientação r para } \\
\text { tomadores de decisão, } \\
\text { gestores de saúde e } \\
\text { profissionais de saúde } \\
\text { sobre o uso de } \\
\text { máscaras cirúrgicas e } \\
\text { respiradores. }\end{array}$ & $\begin{array}{l}\text { Relatório } \\
\text { técnico }\end{array}$ & $\begin{array}{llr}\text { Máscaras } & \text { cirúrgicas: } & \text { no } \\
\text { atendimento } & \text { direto } & \text { ao } \\
\text { paciente com } & \text { COVID-19 a } 1 \\
\text { metro de } & \text { distância. } \\
\text { Respirador: N95 ou PFF2 ou } \\
\text { PFF3 em procedimentos que } \\
\text { geram aerossóis. }\end{array}$ & $\begin{array}{l}\text { Máscara cirúrgica/ } \\
\text { N95/PFF2/PFF3 }\end{array}$ & $\begin{array}{l}\text { Os tomadores de decisão } \\
\text { devem considerar a } \\
\text { viabilidade } \\
\text { implementação de uma } \\
\text { política de uso contínuo de } \\
\text { máscara para todos os } \\
\text { profissionais de saúde. }\end{array}$ \\
\hline $\begin{array}{l}\text { Departamento } \\
\text { de Saúde do }\end{array}$ & $\begin{array}{c}\text { COVID-19: } \\
\text { INFECTION } \\
\text { PREVENTION AND } \\
\text { CONTROL } \\
\text { GUIDANCE } \\
\text { Department of } \\
\text { Health and Social } \\
\text { Care (DHSC), Public }\end{array}$ & $\begin{array}{l}\text { Reino } \\
\text { Unido/ }\end{array}$ & $\begin{array}{l}\text { Descrever medidas de } \\
\text { prevenção e controle } \\
\text { de contaminação para } \\
\text { profissionais de saúde } \\
\text { que são responsáveis } \\
\text { por receber, avaliar e } \\
\text { cuidar de pacientes } \\
\text { com sinais e sintomas } \\
\text { suspeitos ou para }\end{array}$ & $\begin{array}{l}\text { Relatório } \\
\text { técnico }\end{array}$ & \begin{tabular}{|l} 
Máscara cirúrgica tipo IIR: \\
entrar em uma área \\
internação \\
suspeitos ou confirmados de \\
COVID-19, envolvendo ou \\
não cuidados diretos a \\
metros de distância do \\
paciente. Respiradores: PFF3 \\
em área de internação de alto
\end{tabular} & $\begin{array}{l}\text { Máscara cirúrgica } \\
\text { resistente a fluidos (tipo }\end{array}$ & 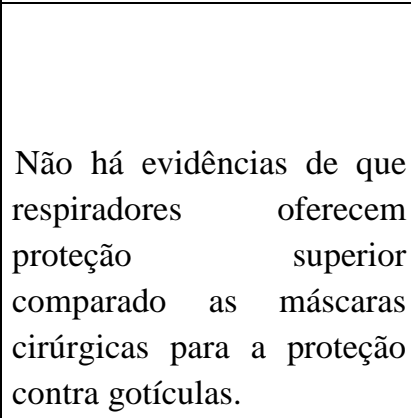 \\
\hline
\end{tabular}


Research, Society and Development, v. 10, n. 1, e16710111628, 2021

(CC BY 4.0) | ISSN 2525-3409 | DOI: http://dx.doi.org/10.33448/rsd-v10i1.11628

\begin{tabular}{|c|c|c|c|c|c|c|c|}
\hline Reino Unido & \begin{tabular}{|} 
Health Wales (PHW), \\
Public Health Agency \\
(PHA) Northern \\
Ireland, Health \\
Protection Scotland \\
(HPS), Public Health \\
Scotland, Public \\
Health England and \\
NHS England/ 2020
\end{tabular} & Inglesa & $\begin{array}{l}\text { casos confirmados de } \\
\text { COVID-19. }\end{array}$ & & $\begin{array}{l}\text { risco, com procedimentos } \\
\text { geradores de aerossol. }\end{array}$ & IIR)/Respirador PFF3 & \\
\hline $\begin{array}{c}\text { Centro de } \\
\text { Prevenção e } \\
\text { Controle de } \\
\text { Doenças (CDC) } \\
\text { dos Estados } \\
\text { Unidos da } \\
\text { América }\end{array}$ & $\begin{array}{c}\text { INTERIM } \\
\text { INFECTION } \\
\text { PREVENTION } \\
\text { ANDCONTROL } \\
\text { RECOMMENDATION } \\
\text { S FOR } \\
\text { HEALTHCARE } \\
\text { PERSONNEL } \\
\text { DURING THE } \\
\text { CORONAVIRUS } \\
\text { DISEASE 2019 } \\
\text { (COVID- } \\
\text { 19)PANDEMIC } \\
\\
\text { National Center for } \\
\text { Immunization and } \\
\text { Respiratory Diseases } \\
\text { (NCIRD) / 2020 }\end{array}$ & $\begin{array}{c}\text { Estados } \\
\text { Unidos da } \\
\text { América/ } \\
\text { Inglesa }\end{array}$ & 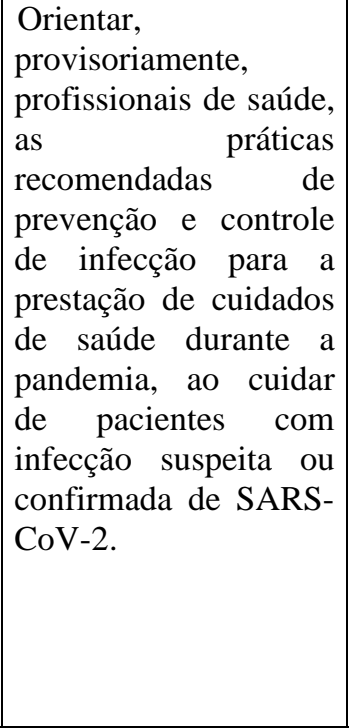 & $\begin{array}{l}\text { Relatório } \\
\text { técnico }\end{array}$ & $\begin{array}{l}\text { Respirador:N95,equivalente } \\
\text { ou de nível superior (PAPRs } \\
\text { ou elastoméricos): em área } \\
\text { de cuidados de rotina, a } 1 \\
\text { metro de distância do } \\
\text { paciente ou durante a } \\
\text { realização de procedimentos } \\
\text { geradores de aerossol. }\end{array}$ & $\begin{array}{c}\text { Máscara } \\
\text { cirúrgica/Respirador } \\
\text { N95 e equivalente, } \\
\text { PAPRs/Respiradores } \\
\text { elastoméricos }\end{array}$ & $\begin{array}{l}\text { Recomenda } \\
\text { implementação de um } \\
\text { programa de proteção } \\
\text { respiratória para locais que } \\
\text { prestam cuidados a } \\
\text { pacientes com infecção para } \\
\text { os quais um respirador é } \\
\text { recomendado. }\end{array}$ \\
\hline
\end{tabular}

Fonte: Autores (2020).

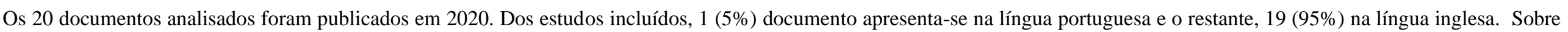

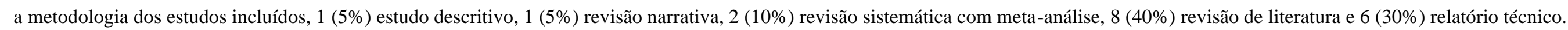


Os estudos E1, E3, E5, E6, E10 e E12 recomendam o uso de máscaras cirúrgicas para os profissionais de saúde quando estiverem prestando cuidados diretos, que não incluam procedimentos geradores de aerossóis, a pacientes com sintomas sugestivos de COVID-19 ou confirmado. Esses trabalhos também avaliaram que o uso de respiradores N95/FFP2 deve ser reservado quando realizado procedimentos invasivos e que gerem aerossóis. Os trabalhos E10 e E14 também destacam que ainda não existem estudos que comprovem uma vantagem ou efeito protetor justificável para estender o uso de respiradores N95/FFP2 em procedimentos que não geram aerossóis.

O estudo E2, especifica o tipo de máscara cirúrgica (tipo 2), assim como o estudo E7, que indica máscara cirúrgica resistente a fluidos, (IIR), para os profissionais de saúde, na realização de cuidados de rotina, em pacientes suspeitos ou confirmados de infecção por COVID-19. No geral, ambos os trabalhos recomendam o uso de respiradores para procedimentos geradores de aerossóis, justificado pela falta de estudos robustos que comprovem um benefício a mais no uso desses EPI`s em procedimentos que não geram aerossóis. Os trabalhos também chamam a atenção para a importância da capacitação dos profissionais de saúde para o uso apropriado dos EPI`s, aliado a outras medidas de controle de infecção, incluindo a higiene completa das mãos.

A recomendação do uso de respiradores N95, PFF2 e PFF3 para cuidados de rotina, no atendimento direto a pacientes suspeitos e confirmados da COVID-19, estão presentes nos artigos E4, E8, E11 e E13. Os artigos E8 e E11 também mencionam respiradores purificadores de ar (PAPRs), e indicam sua utilização em procedimentos de alto risco. O estudo E14 orienta que o profissional de saúde pode usar tanto uma máscara cirúrgica como um respirador, na prestação de cuidados de rotina, e em procedimentos não geradores de aerossol, em pacientes suspeitos ou confirmados de infecção pela COVID-19. E define o uso somente de respiradores em procedimentos geradores de aerossóis. O estudo também alerta que a proteção do profissional de saúde sem a adoção de medidas de controle de contaminação, como a lavagem correta das mãos, não é garantida.

As diretrizes governamentais e das agências reguladoras apresentadas no quadro 2, também trazem divergências quanto às recomendações de uso de máscaras e respiradores pelos profissionais de saúde. A ANVISA, recomenda o uso de respiradores PFF2 somente em procedimentos geradores de aerossóis, e também menciona a utilização de máscaras de tecido em áreas administrativas e de triagem.

O CDC indica a utilização de respirador N95 ou equivalentes ou superior em área de cuidados de pacientes suspeitos ou confirmados de infecção pela COVID-19, independente da realização ou não de procedimentos que geram aerossóis.

Duas diretrizes abordam também os tipos de máscara cirúrgica recomendada. O Reino Unido indica máscaras cirúrgicas resistentes a fluidos, já o departamento de saúde da Austrália, indica máscaras cirúrgicas tipo 1,2 e 3 a depender do risco de exposição à fluidos corporais. O ECDC e o relatório do Reino Unido, foram os únicos relatórios a especificar a utilização do respirador FFP3 para áreas de internação de alto risco e em procedimentos que geram aerossóis.

Os estudos E5 e os relatórios técnicos da Anvisa do Brasil e da OMS, mencionam um distanciamento de no mínimo 1 metro do paciente. Já a ECDC e o departamento de saúde Australiano, definem essa distância como sendo a 1,5 metros do paciente. O CDC dos Estados Unidos indica um distanciamento mínimo de 1,8 metros. Por fim, o artigo, E7 e o departamento de saúde do Reino Unido, definem a distância de 6 pés (2 metros) do paciente.

O estudo E1 menciona um tempo mínimo de uso da máscara cirúrgica de 4 horas, e para os respiradores particulados, esse tempo não deve ultrapassar as 8 horas de uso. O estudo E2 define o tempo máximo de uso para máscaras cirúrgicas de até 8 horas.

Os artigos E1 e E9 especificam os tipos de procedimentos geradores de aerossóis. Os relatórios técnicos da ANVISA do Brasil, CDC nos Estados Unidos e a OMS, também trazem em seus relatórios uma lista de procedimentos geradores de aerossóis. Os demais relatórios técnicos e artigos científicos não especificam quais seriam eles. 


\section{Discussão}

Esta revisão de escopo reuniu artigos e relatórios técnicos, que atenderam aos objetivos da pesquisa, sobre as recomendações de uso de máscaras cirúrgicas e respiradores por profissionais de saúde, no contexto de risco de contaminação pelo novo coronavírus, o SARS-CoV-2. Embora, haja concordância sobre a importânciada utilização de máscaras, foram divulgadas recomendações conflitantes em relação ao tipo de máscara/ respirador indicado e as circunstâncias de uso.

O uso de protetores respiratórios está em voga, e os questionamentos sobre a indicação mais segura, de acordo com o cenário de exposição. Isso se dar pelo contexto da pandemia pelo novo coronavírus, em que a proteção dos profissionais de saúde contra a contaminação baseia-se no uso de equipamentos de proteção individual (Lepelletier \& Grandbastien et al., 2020).

É interessante notar que desde a eclosão da SARS-CoV-1 em 2002 tem havido um elevado nível de controvérsia na determinação das formas ideais de proteger os profissionais de saúde dos patógenos respiratórios o que reflete em recomendações conflitantes sobre as máscaras cirúrgicas e respiradores particulados (Smith, 2016; Jackson, 2020).

Há muitos questionamentos de instituições e profissionais de saúde sobre se as máscaras cirúrgicas oferecem proteção suficiente, no atendimento de rotina em pacientes com COVID-19. Na amostra desta revisão de escopo há duas Meta-Análises (Bartoszko et al., 2020; Wu, M. M et al., 2020), que comparam a eficácia das máscaras cirúrgicas com respiradores N95.Ambos os estudos não conseguiram realizar uma Meta-Análise para o SARS-CoV-2. Os estudos apontam que ainda não há evidências convincentes de que máscaras cirúrgicas sejam inferiores aos respiradores N95, em cuidados de rotina e procedimentos que não geram aerossóis. Porém, os estudos frisam que ainda não há evidências sobre o efeito protetor de máscaras cirúrgicas e respiradores especificamente para o SARS-CoV-2 (Bartoszko et al., 2020).

As evidências apresentadas pelos dois estudos de meta-análise, sugerem a necessidade de novos estudos com metodologia de alta qualidade, com grupo controle, e critérios de inclusão e exclusão estritamente definidos, e considere fatores que possam interferir nos resultados (vedação dos respiradores, higiene das mãos, entre outros.), e que abordem especificamente a eficácia dos EPI's respiratórios contra o novo coronavírus. Os estudos também recomendam, de acordo com as evidências científicas atuais, a precaução para gotícula, em cuidados de rotina e procedimentos não geradores de aerossol e precaução respiratória para aerossóis, quando há a execução de procedimentos geradores de aerossóis. Essa recomendação está de acordo com a divulgada pela OMS e ANVISA (Brasil, 2020; Organização Mundial da Saúde, 2020).

A falta de compreensão dos mecanismos detalhados de transmissão do SARS-CoV-2 pode explicar a discrepância da recomendação para proteger os profissionais de saúde. Além disso, a alta transmissibilidade do vírus, e sua taxa de letalidade ( $0,5 \%$ a 3,5\%), são indicadores que provavelmente influenciaram na tomada de decisão (Sommerstein et al., 2020).

Artigos científicos e relatórios técnicos também recomendam o distanciamento que o profissional de saúde deve ter do paciente, apresentado na amostra como de 1 a 2 metros de distância. No entanto, estudos anteriores que apoiam essas distâncias utilizaram métodos desatualizados ao considerar a dicotomia gotículas versus aerossóis, e ao desconsiderar os diversos fatores que podem interferir na dispersão das gotículas, como a carga viral do hospedeiro, duração da exposição de indivíduos infectados, ambientes internos versus externos, ventilação de ar, uso máscaras cirúrgicas e respiradores particulados, atividades que projetam partículas pelo ar em distâncias maiores como nuvens de gás exalado: ao cantar, tossir ou na respiração pesada (Jones, 2020).

A rápida disseminação internacional do SARS-CoV-2 também sugere que o uso de cortes arbitrários de tamanho de gota (gotículas $>5 \mu \mathrm{m}$ e aerossóis $\leq 5 \mu \mathrm{m}$ ) pode não refletir com precisão o que realmente ocorre nas disseminações de partículas respiratórias. Existem diversos estudos observacionais que sustentam a hipótese que a contaminação pelo SARSCoV-2 se dá além dos 2 metros, como os relatórios de 2020 da China, que encontrou partículas do vírus do SARS-CoV-2 nos sistemas de ventilação em quartos de hospitais de pacientes com COVID-19. Esse e diversos outros achados são consistentes com a hipótese do modelo de nuvem de gás turbulenta, onde há um aglomerado de gotículas de diferentes tamanhos que em 
associação com fatores ambientais, como umidade e temperatura, essas gotículas podem viajar de 7 a 8 metros de distância (Setti, 2020; Anderson, 2020; Bourouiba, 2020).

Também foi identificado na amostra, artigos que especificam tipos de procedimentos geradores de aerossóis (E1, E9, ANVISA, CDC e OMS) e entre eles há divergência de quais seriam esses procedimentos. Há também artigos e relatórios técnicos que não mencionam os tipos de procedimentos só mencionam o termo “procedimentos geradores de aerossóis”. Esse termo se tornou popular na epidemia de SARS-CoV-1 em 2002, quando essa fonte foi suspeita de infecção, assim como no surto causado pelo vírus influenza H1N1, a epidemia causada pelo MERS e Ebola (Jackson, 2020).

Uma revisão de literatura (O’Neil, Caroline et al., 2017), avalia que as diretrizes atuais para profissionais de saúde que participam de procedimentos suspeitos de geração de aerossóis tiveram que se basear em evidências mínimas ou de baixa qualidade. Dessa forma, as incertezas quanto à classificação dos procedimentos geradores de aerossóis, como observada nos estudos dessa amostra, torna difícil para os hospitais elaborar os protocolos de prevenção de infecção e também gera discordâncias quanto ao tipo de EPI respiratório a ser usado.

A recomendação de uso do respirador purificador de ar (PARPRs) foram mencionadas em duas revisões sistemáticas (Petsonk \& Harber, 2020; Lynch J. B., et al., 2020) uma revisão de literatura (Edward L, 2020), e por relatórios técnicos emitidos pelo Centro de Saúde Australiano e o CDC dos Estados Unidos. Os PARPRs foram utilizados principalmente no surto de SARS-CoV-1. Uma vantagem apresentada por esses tipos de EPIé sua reutilização, principalmente em momentos de escassez de respiradores descartáveis, como vivenciados nesta pandemia. Entretanto, seu uso, assim como para outros respiradores, precede de treinamento e programas de manutenção robustos para garantir bom uso, e consequentemente, sua eficácia (Park, 2020).

A eficácia dos dispositivos de proteção respiratória não se faz de forma isolada, e independente de outros fatores, alguns trabalhos científicos (Azap \& Erdinç, 2020; Umer F et al., 2020; Lynch J. B et al., 2020), também chamaram a atenção para a importância da capacitação dos profissionais de saúde, no que diz respeito a utilização dos EPI's e medidas de precaução padrão. Os respiradores precisam passar por testes de ajuste, e o profissional de saúde deve observar a vedação antes do uso, a colocação e retirada também é um ponto importante, e deve ser adequada, e qualquer manuseio de máscaras e respiradores deve ser precedido da higienização adequada das mãos.

\section{Considerações Finais}

As recomendações quanto ao uso de máscaras/respiradores de proteção respiratória para os profissionais de saúde em risco de exposição ao SARS-CoV-2 apresentadas nesta revisão de escopo são conflitantes em relação ao: a) Tipo de proteção respiratória em cuidados de rotina, quando não há geração de aerossóis, com estudos que indicam a utilização de máscaras cirúrgicas e outros que recomendam a utilização de um respirador particulado; b) Há uma variação de diferentes respiradores particulados de diversos graus de proteção para o mesmo cenário de exposição clínica; C) Existe conflito quanto ao cenário de maior exposição para os profissionais de saúde, na discordância de quais procedimentos geram aerossóis.

Esta revisão de escopo, frisa a necessidade de estudos primários com rigor metodológico para produção de evidências mais robustas sobre o efeito protetor de máscaras e respiradores (N95, PFF2 e superiores), especificamente com relação ao SARS-CoV-2, e fatores que podem interferir na proteção adequada, como a capacitação dos profissionais de saúde, o uso adequado do EPI e a higienização das mãos.

Também avalia a necessidade de estudos robustos atualizados sobre a dispersão de gotículas e aerossóis, com métodos que considerem os diversos fatores que interferem na trajetória dessas gotículas, e que possa superar a antiga dicotomia entre gotículas versus aerossóis. Essa percepção atual pode limitar as recomendações de saúde pública, interfere em escolhas mais assertivas de proteção respiratória para os profissionais de saúde e consequentemente na eficácia das intervenções propostas. 
Por se tratar de um vírus de transmissão respiratória emergente, até a conclusão desta revisão de escopo, não foi possível coletar estudos que avaliassem a proteção respiratória especificamente para o SARS-CoV-2. Dessa forma, os resultados apresentados sustentam a importância da realização de pesquisas futuras robustas para ampliar e aprofundar as evidências científicas que envolvem essa temática, por meio de ensaios randomizados e de metanálise.

\section{Referências}

Ağalar, C., \& Engin, D. Ö. (2020).Protective measures for COVID-19 for healthcare providers and laboratory personne. Revista turca de ciências médicas. 50,578-584.10.3906/sag-2004-132.

Anderson, E. L., Turnham, P., Griffin, J. C., \& Clarke, C. C (2020). Consideration of the Aerosol Transmission for COVID-19 and Public Health. Risck Analysis. 40(5). https://doi.org/10.1111/risa.13500.

Australian Government (2020, May). Guidance on the use of personal protective equipment (PPE) in hospitals during the COVID-19 outbreak, v.5. https://www.health.gov.au/resources/publications/guidance-on-the-use-of-personal-protective-equipment-ppe-in-hospitals-during-the-covid-19-outbreak.

Azap, A., \& Erdinç, F. (2020). Medical mask or N95 respirator: When and how to use? Turk J MedSci. 50(1), 633-637. https://doi.org/10.3906/sag-2004-199.

Bartoszko, J. J., Farooqi, M. A. M., Alhazzani, W., \& LOEB, M. (2020). Medical masks vs N95 respirators for preventing COVID-19 in healthcare workers: A systematic review and meta-analysis of randomized trials. Influenza ando ther Respiratory Viruses.14(4), 365-373. https://doi.org/10.1111/irv.12745.

Bourouiba, L. (2020). Turbulent Gas Clouds and Respiratory Pathogen Emissions. Jama. 323 (18), 1837-1838. 10.1001/jama.2020.4756.

Brasil. Agência Nacional de Vigilância Sanitária (ANVISA) (2020). Nota técnica 07/2020-GVIMS/GGTES/ANVISA-Orientações para prevenção e vigilância epidemiológica das infecções por sars-cov-2 (covid-19) dentro dos serviços de saúde. (complementar à nota técnica gvims/ggtes/anvisa ${ }^{\circ}$ 04/2020). https://www20.anvisa.gov.br/segurancadopaciente/index.php/alertas?task=callelement\&format=raw\&item_id=855\&element=f85c494b-2b32-4109-b8c1083cca2b7db6\&method=download\&args[0]=912a2edf85fe0367a04ff6eb7ccde989.

Centers for Disease Control and Prevention (2020). Coronavirus Disease 2019 (COVID-19): Interim Infection Prevention and Control Recommendations for Healthcare Personnel During the Coronavirus Disease 2019 (COVID-19) Pandemic. Centers for Disease Control and Prevention. USA, (d). https://www.cdc.gov/coronavirus/2019-ncov/hcp/infection-control-recommendations.html

Cook, T. M. (2020). Personal protective equipment during the coronavirus disease (COVID) 2019 pandemic - a narrative review. Anaesthesia.75 (7), $920-927$. https://doi.org/10.1111/anae.15071.

European Centre for Disease Prevention and Control (2020). Guidance for wearing and removing personal protective equipament in healthcare settings for the care of patients with suspected or confirmed COVID-19. Estocolmo (a). https://www.ecdc.europa.eu/en/publications-data/guidance-wearing-and-removingpersonal-protective-equipment-healthcare-settings.

Fehr, A. R., \& Perlman, S. (2015). Coronaviruses: an Overview of their replication an pathogeneses. Methods in Molecular Biology.1282, 123.https://doi.org/10.1007/978-1-4939-2438-7_1.

Friese, C. R., Veenema, T. G., Johnson, J. S., Jayaraman, S., Chang, J. C., \& Clever, L. H. (2020). Respiratory Protection Considerations for Healthcare Workers during the COVID-19 Pandemic. Health Security.18 (3), 237-240. https://doi.org/10.1089/hs.2020.0036.

Gordon, C., \& Thompson, A. (2020). Use of personal protective equipment during the COVID-19 pandemic. British Journal of Nursing. 29(13), 748-752. https://www.researchgate.net/deref/http\%3A\%2F\%2Fdx.doi.org\%2F10.12968\%2Fbjon.2020.29.13.748.

Ha, J. F. (2020). The protective equipment, and respirator: a narrative review. Int J Clin 74 (10), e 13578. https://doi.org/10.1111/ijcp.13578.

Helioterio, M. C., Lopes, F. Q. R. de S., de Souza, C. C., Souza, F. de O., Pinho, P. de S., Souza, F. N. F. de, \& de Araújo, T. M. (2020). COVID-19: Por que a proteção de trabalhadores e trabalhadoras de saúde é prioritária no combate à pandemia? Trabalho, Educação e Saúde. 18(3), e00289121.https://doi.org/10.1590/1981-7746-sol00289.

Hirschmann, M. T., Hart, A., Henckel, J., Sadoghi, P., Seil, R., \& Mouton, C. (2020). COVID-19 coronavirus: recommended personal protective equipment for the orthopaedic and trauma surgeon. KneeSurgery, Sports Traumatology, Arthroscopy. 28(6), 1690-1698. https://doi.org/10.1007/s00167-020-06022-4.

Jackon, T. et al. (2020). Classification of aerosol-generation procedures: a rapid systematic review. BMJ Open Respiratory Research. 7(1).

Jiang, F. et al. (2020). Review of the Clinical Characteristics of Coronavirus Disease 2019 (COVID-19). J Gen Intem Med.35(5). https://doi.org/10.1007/s00167-020-06022-4.

Jones, N. R., Qureshi, Z. U., Temple, R. J., Larwood, J. P. J., Greenhalgh, T., \& Bourouiba, L. (2020). Two metres or one: what is the evidence for physical distancing in COVID-19? Bmj.370.http://dx.doi.org/10.1136/bmj.m3223.

Kaswa, R., \& Govender, I. (2020). Novel coronavirus pandemic: A clinical overview. South African Family Practive. 62(1). https://doi.org/10.4102/safp.v62i1.5123.

Lana, R. M. et al. (2020). Emergência do Novo Coronavírus (SARS-CoV-2) e o Papel de uma Vigilância Nacional em Saúde Oportuna e Efetiva. Cadernos de Saúde Pública. 36(3). https://doi.org/10.1590/0102-311x00019620.

Lepelletier, D., \& Grandbastien, B. et al. (2020). What face mask for what use in the context of COVID-19 pandemic? The French guidelines. Journal of Hospital Infection.105(3), 414-418.https://doi.org/10.1016/j.jhin.2020.04.036. 
Lynch, J. B. et al. (2020). Infectious diseases society of America guidelines on infection prevention in patients with suspected or known COVID-19. Infectious Diseases Societyof America Guideli. https://www.idsociety.org/practice-guideline/covid-19-guideline-infection-prevention/.

Ministério da Saúde. Secretaria de Vigilância em Saúde (2020). Recomendações de proteção aos trabalhadores dos serviços de saúde no atendimento de COVID-19 e outras síndromes gripais. https://www.saude.go.gov.br/files/banner_coronavirus/GuiaMSRecomendacoesdeprotecaotrabalhadores-COVID19.pdf.

Ministério da Saúde. Secretaria de Vigilância em Saúde. Boletim Epidemiológico Especial: Doença pelo coronavírus COVID-19. http://coronavirus.saude.gov.br/boletins epidemiológicos.

Moher, D. et al. (2009). Preferred Reporting Items for Systematic Reviews and Meta-Analyses the Prisma Statement. https://doi.org/10.1371/journal.pmed.1000097.

Munn, Z. et al. (2018). Systematic review or scoping review? Guidance for authors when choosing between a systematic or scoping review approach. BMC Medical Research Methodology. https://doi.org/10.1186/s12874-018-0611-x.

National Health Service. (2020). COVID-19: Infection prevention and control guidance, United Kingdom, v.3. https://www.gov.uk/government/publications/wuhan-novel-coronavirus-infection-prevention-and-control/covid-19-personal-protective-equipment-ppe.

O'Neil, C. A. et al. (2017). Caracterization of Aerosols Generated During Patient Care Activities. Clin Infect Dis. 65(8), 1335-1341. https://doi.org/10.1093/cid/cix535.

Organização Mundial de Saúde (2020). Orientação sobre o uso de máscaras no contexto da COVID-19. Tradução de OPAS- Brasília: Organização PanAmericana de Saúde, 2020. https://iris.paho.org/handle/10665.2/51994.

Organização Panamericana de Saúde. Organização Mundial de Saúde (2020). OMS afirma que COVID-19 é agora caracterizada como pandemia. Genebra. https://www.paho.org/bra/index.php?option=com_content\&view=article\&id=6120:oms-afirma-que-covid-19-e-agora-caracterizada-comopandemia\&Itemid=812.

Organización Panamericana de La Salud (2020). Organização Mundial de laSalud. Alerta Epidemiológica: COVID-19 em personal de salud. https://www.paho.org/es/documentos/alerta-epidemiologica-covid-19-personal-salud-31-agosto-2020.

Park, S. H. (2020). Personal Protective Equipment. For Healthcare Workers during the COVID-19 pandemic. Infect Chemother. 52(5), 165-182. https://www.researchgate.net/deref/http\%3A\%2F\%2Fdx.doi.org\%2F10.3947\%2Fic.2020.52.2.165.

Peters, M. D. J. et al. (2020). Chapter11: Scoping Reviews (2020 version). JBI Manual for Evidence Synthesis. https://wiki.jbi.global/display/MANUAL/Chapter+11\%3A+Scoping+reviews.

Petsonk, E. L., \& Harber, P. (2020). Respiratory protection for health care workers: A 2020 COVID-19 perspective. American Journal of Industrial Medicine. 6. https://doi.org/10.1002/ajim.23144.

Setti, L. et al. (2020). Airborne transmission route of COVID-19: why 2 meters/6 feet of inter-personal distance could not be enough. Int. J.E. Res. Public Health. 17(8),2932. https://doi.org/10.3390/ijerph17082932.

Sharma, A. et al. (2020). Severe acute respiratory syndrome coronavirus-2 (SARS-CoV-2): A global pandemic and treatment strategies. International Journal of Antimicrobial Agents. 56(2), 106054. https://doi.org/10.1016/j.ijantimicag.2020.106054.

Smith, J. D. et al. (2016). Effectiveness of N95 Respirators versus surgical masks in protecting health care workers from acute respiratory infection: a systematic review and meta-analysis.CMAJ. 188(8), 567-574. https://doi.org/10.1503/cmaj.150835.

Sommerstein, R., \& Fux, C. A., et al. (2020). Risk of SARS-CoV-2 transmission by aerosols, the rational use of masks, and protection of healthcare workers from COVID-19. Antimicrobial Resistance and Infection Control, 9 (1), 100. https://doi.org/10.1186/s13756-020-00763-0.

Teixeira, C. F. de S.et al. (2020). A Saúde dos profissionais de saúde no enfrentamento da pandemia de COVID-19. Ciência e Saúde coletiva. 25(9). http://dx.doi.org/10.1590/1413-81232020259.19562020.

Thomas, J. P., Srinivasan, A., Wickramarachchi, C. S., \& Dhesi, P. K. et al. (2020). Evaluating the national PPE guidance for NHS healthcare workers during the COVID-19 pandemic. Clinical Medicine. 20(3), 242-247. https://doi.org/10.7861/clinmed.2020-0143.

Tricco, A. C. et al. (2018). Prisma Extension for Scoping Reviews (PRISMA-ScR): Checklist and Explanation. Ann Intern Med. 169(7), 467-473. https://doi.org/10.7326/m18-0850.

Umer, F., Haji, Z., \& Zafar, K. (2020). Role of respirators in controlling the spread of novel coronavirus (COVID-19) amongst dental healthcare providers: a review. International Endodontic Journal. 53(8), 1062-1067. https://doi.org/10.1111/iej.13313.

Wold Health Organization (WHO). (2020). Clinical management of COVID-19: Interim guidance. Genebra: WHO. https://www.paho.org/en/documents/clinical-management-covid-19-interim-guidance-who. 